\title{
Communicating openly: SAJCD is now an open-access journal
}

The Internet has revolutionised publishing, and journal articles are now primarily accessed electronically. In 2005 European online sales in scientific, technical and medical publishing surpassed print sales for the first time (Mort, 2006). In 2009 nearly $10 \%$ of all scientific, technical and medical journals were published using an open-access model (Pollock, 2009).

Open-access literature is online, available to all, free of charge and free of most copyright and licensing restrictions. It is made possible through the Internet and the consent of the author/s (Suber, 2004). This issue of the South African Journal of Communication Disorders is our first openaccess edition, available to all online at http://www.sajcd.org.za/index. php/SAJCD - an important milestone for the journal, which has come a long way since its inception in 1948.

\section{Looking back}

SAJCD was first published as the Journal of Logopedics in March 1948. The editor, Rhona Gorvy, gives a fascinating insight into the professions at that time. Focusing mainly on 'speech therapy' rather than audiology, she exhorts colleagues to engage with the papers therein and notes that:

范 of \%

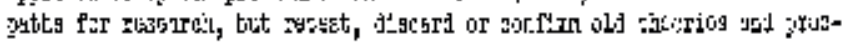

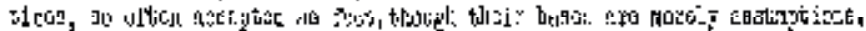

While much has changed in the profession since that time - not least the disappearance of terminology that now makes us shudder (e.g. clients referred to as 'speech deviates' or 'hearing deviates') - there is much in this first volume that is still pertinent today: a call for closer co-operation between education and health; awareness and promotion of CPD events; and a call to provide services to all the 'different racial groups' through mobile clinics in rural districts. This latter point is especially poignant since 1948 is the year in which apartheid was introduced as an official policy in South Africa following the general election.

In 1954 the journal became known as the Journal of the South African Logopedic Society, and a further name change occurred in 1971, to the Journal of the South African Speech and Hearing Association. The annual subscription fee at this time was R1.50. In 1977 the journal became the South African Journal of Communication Disorders, and the subscription was upped to R2.50.

Professor Brenda Louw, editor of the SAJCD in 1994 - another milestone year - outlined some of the challenges of editing the journal (Louw, 1994), the ultimate one being whether a scientific publication in the fields of speech-language pathology and audiology is at all relevant to the South African situation. The alternative to scientific publication is informal dissemination of clinical information, e.g. through newsletters and study groups. She concluded that such a publication is indeed important: 'The time and effort invested in the publication process by the author, reviewers and editors is justified to help create an important body of knowledge in the field. This is specifically true of the South African situation in which a dearth of knowledge still exists regarding communication disorders and service delivery in the local context.' ( $\mathrm{p}$. 106). The question raised by Louw (1994) has been raised often since then. Claire Penn (2007) described a crisis in the professions due to a widening chasm between clinical practice and scientific research. She noted that 'without the discipline of science, we will simply remain a group of practicing clinicians and we will never achieve mastery or acknowledgement. We can "practice" doing science but what is needed is for science to be done with authority, with an audience, with peerreview, with argumentation and with energy.' (p. 15).

\section{Looking forwards}

Open-access publishing is entirely compatible with peer review, one of the aspects mentioned by Penn (2007). All of the major open-access initiatives for scholarly literature insist on the importance of the peer review process in promoting and maintaining the highest standards of scientific research. SAJCD has always relied on peer review, but this process itself is not without challenges: the pool of appropriately qualified and available reviewers is small, and the time-consuming task of review is uncompensated and voluntary. Many of the authors of journal papers are drawn from this same pool. Please consider signing up as a peer reviewer if you are able, and developing your research and writing skills. Clinicians can engage in research and are often in the best position to do so! Our new CPD section (see back of journal) encourages engagement with the journal and application of findings to one's own practice. We hope that you will find this a useful avenue for obtaining CPD points.

Contrary to popular belief, open-access literature is not free or cheap to produce, although it is less expensive to produce than conventionally published literature. Advocates of online publishing ask whether there are better ways to pay the bills than by charging readers and creating access barriers. Looking forwards we will have to consider the costeffectiveness of $S A J C D$, and whether a printed copy is necessary. In general, the success of online, open-access publications has assuaged concerns about the permanency and impact of online-only articles. Please let us know whether you would be happy to no longer receive a printed journal, and perhaps save a few trees in the process.

We believe strongly that the journal has a critical role to play in the professions in South Africa. We aim to advocate and endorse a full range of research methods, strive for excellence, and ask for help when it is required. But we are aware that the existence of the journal is not something to be taken for granted, and its future is not necessarily secure. It relies on those who contribute to it - as authors, reviewers, editors and readers - and we may need to fight for its survival, if we, like Louw and Penn, wish the professions in South Africa to achieve mastery through research.

We encourage our readers and authors to contact the journal (michelle. pascoe@uct.ac.za) with suggestions for what more we can offer the professions of speech-language pathology and audiology, as we usher in the latest phase of the evolution of SAJCD (http://www.sajcd.org.za/ index.php/SAJCD).

\section{Michelle Pascoe}

Editor-in-Chief

\section{References}

Gorvy, R. (1948). Editorial. Journal of Logopedics, 1, 1.

Louw, B. (1994). Editing a scientific journal on communication disorders in South Africa: A unique challenge. South African Journal of Communication Disorders, 41, 103-107.

Mort, D. (2006). Online passes print in STM publishing. Research Information. http://www. researchinformation.info/riaugsep06analysis.html

Penn, C. (2007). 'Don't give me the theory, just tell me what to do in therapy!': The slippery slope challenge for the South African professions of speech-language pathology and audiology. South African Journal of Communication Disorders, 54, 13-17.

Pollock, D. (2009). An Open Access Primer - Market Size and Trends. Outsell Inc. http:// www.outsellinc.com/store/products/873

Suber, P. (2004). A very brief introduction to open access. http://www.earlham.edu/ peters/ fos/brief.htm 